\title{
Making the paper: reactive rocks
}

\section{Peridotite rocks in Oman show promise for carbon sequestration.}

In the arid, stony mountains of northern Oman, locals gather water for palm-tree gardens from spectacular blue ponds fed by underground springs. But chemical reactions beneath the rocks have made the water so alkaline - the ponds' $\mathrm{pH}$ can be a deadly 11 or 12 - that it won't be used right away. Even the formation of a chalky white calcium precipitate at the bottom of the ponds, lending them their bright blue colour, is insufficient to mellow the water. Instead it is transferred to basins where the concrete sides react further with carbon dioxide sucked out of the atmosphere, bringing the water to a neutral, garden-ready $\mathrm{pH}$.

A similar process is simultaneously at work under the mountains' surface. Where groundwater trickles through the stones, they also react with $\mathrm{CO}_{2}$ from the air - much faster than geologists had suspected, according to research published this month (Proc. Natl Acad Sci USA 105, 17295-17300; 2008). Omani rocks of a type known as peridotite devour up to 100,000 tons of atmospheric $\mathrm{CO}_{2}$ each year, say geoscientists Peter Kelemen and Jürg Matter of Columbia University's Lamont-Doherty Earth Observatory in

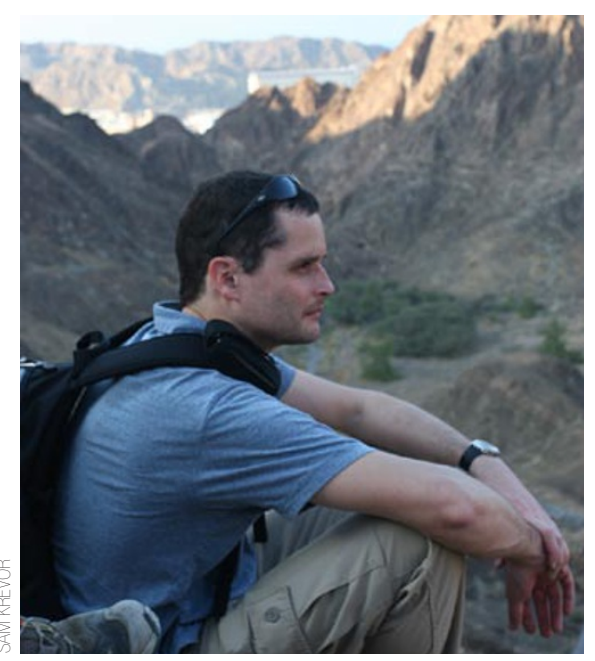

Jürg Matter
New York. Artificially speeding the reaction, they suggest, could soak up vast quantities of $\mathrm{CO}_{2}$ emitted by nearby power plants and oil and gas fields.

The idea was born three years ago, after Matter gave a seminar on capturing $\mathrm{CO}_{2}$ by reacting it with the calcium compounds in basaltic rock. Kelemen excitedly suggested that the fields of magnesium-rich peridotite in Oman might work just as well. "That's how it started," says Matter.

Both scientists had already done research at the site, which is famous as one of Earth's few surface examples of the mantle rock peridotite. But on their past field trips, they paid little mind to the whitish carbonate formations crusting the surface and running in criss-crossed veins through the stone. The 96-million-year-old peridotite was of interest, says Matter; "the white stuff was just dirt."

Geologists knew that the white deposits near spring-fed surface ponds had been laid down recently. But most subterranean veins were assumed to be nearly as old as the surrounding rock, formed when part of today's Arabian continent lay beneath the sea. In January 2008, Matter and Kelemen travelled to Oman to take another look.

For three weeks, they mapped the dimensions of the carbonated rock and sampled white veins exposed by newly cut roads through the mountains. As reward for their labours, the site offered only the hostile ponds. Matter recalls "hot weather at $30{ }^{\circ} \mathrm{C}$, doing fieldwork - and then you have these wonderful pools, and you cannot go in for a swim."

The pay-off came when the mineral samples were sent back to the laboratory for carbon dating, which revealed ages in thousands of years, not tens of millions, as previously believed. Until these results, "we had no clue about the age of the carbonates and we had no information about the volumes," says Matter. The new numbers show the veins average 26,000 years old and are still forming at a surprisingly brisk pace.

Accelerating this below-ground process could help stave off climate change, believe Kelemen and Matter. Instead of mining

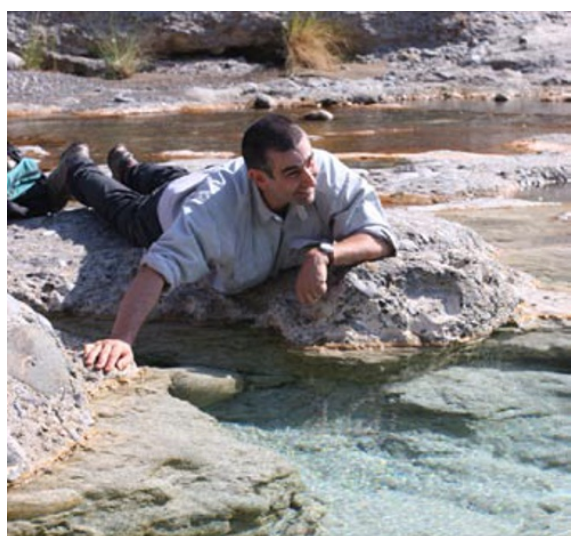

Peter Kelemen

and grinding peridotite, then exposing it to $\mathrm{CO}_{2}$ captured at smokestacks or drillingfields - an expensive and energy-intensive plan suggested in the past - they propose taking the $\mathrm{CO}_{2}$ to the rapidly reacting rock.

Because the carbonation reaction produces heat, says Matter, "it's more or less self-sustainable" after an initial energy kick. That could mean boring into the Omani rocks and injecting purified $\mathrm{CO}_{2}$ along with a burst of hot water to start the reaction. An alternative strategy, say Kelemen and Matter, is to drill peridotite deposits under the Arabian Sea and pump $\mathrm{CO}_{2}$-rich surface sea water down below the bed-rock to be drained of its carbon. Such schemes could speed up peridotite's natural weathering process a million-fold, they estimate, permanently sequestering at least 1 billion tons of $\mathrm{CO}_{2}$ a year in Oman alone.

That makes peridotite a promising addition to the roster of rocks that might be able to gobble up our carbon emissions in future. The team's measurements reveal that "peridotite is another option," concludes Matter. "And we need a lot of options."

Published online: 27 November 2008

doi: 10.1038/climate.2008.131

Anna Barnett 